\title{
PROCESSO DE USO E OCUPAÇÃO NO ESTUÁRIO DO RIO ACARAÚ - CEARÁ E ÁREAS ADJACENTES, UMA ANALISE MULTITEMPORAL DAS FORMAS DE USO
}

\author{
Paulo Roberto Silva Pessoa ${ }^{(a)}$, Lidriana de Souza Pinheiro ${ }^{(b)}$, Jáder Onofre de Morais ${ }^{(\mathrm{c})}$, Aurilea \\ Bessa Alves ${ }^{(d)}$ \\ (a) Prof. Dr. Curso de Geografia da Universidade Estadual do Ceará - UECE/LGCO, paulorpessoa@gmail.com \\ (b) Profa. Dra. Instituto de Ciências do Mar - Labomar/UFC, lidriana.lgco@gmail.com \\ (c) Prof. Dr. Curso de Geografia da Universidade Estadual do Ceará - UECE/LGCO, jaderonofre@gmail.com \\ (d) Profa. MSc. Rede Estadual de Ensino - SEDUC/CE, leabessa@gmail.com
}

\section{Eixo: DINÂMICA E GESTÃO DE ZONAS COSTEIRAS}

\begin{abstract}
Resumo
Os sucessivos ciclos econômicos que se desenvolveram no litoral cearense durante o século XX e nas primeiras décadas do século atual, baseiam-se na extração de sal marinho, na pesca artesanal e na cadeia econômica associada a pesca da lagosta. Recentemente tem se destacado outras atividades como a carcinicultura, o turismo, a expansão imobiliária nas áreas proximas a faixa praial e mesmo nos tabuleiros costeiros, além da implantação dos grandes parques de aerogeradores. Estas atividades no municipio de Acaraú - CE, só demostram a importância estratégica desse espaço. Por isso a importancia de conhecer a evolução espacial e temporal para availiar se estas atividades são ou serão, ambientalmente sustentáveis. O objetivo deste trabalho foi demonstrar a evolução deste ambiente e identificar as principais formas atuais de uso da terra a partir de mapas temáticos da área utilizando técnicas de geoprocessamento a partir de imagens orbitais dsponíveis dos anos 1985, 2001 e 2014.
\end{abstract}

Palavras chave: Estuário do rio Acaraú; mapas temáticos; paisagem.

\section{Introdução}

O município de Acaraú localiza-se na porção norte do estado do Ceará, aproximadamente 230 quilômetros de Fortaleza. A produção espacial deste munícipio está intrinsecamente ligada a zona costeira, iniciandose a partir de sua ocupação em meados do século XVIII, posteriormente como porto e atualmente como um importante polo pesqueiro e uma destacada região produtora de camarão de cativeiro, além da produção de energia eólica e coco.

O estuário do rio Acaraú encontra-se encaixado entre as cidades de Acaraú e Cruz, e por isso sofre os mais diversos impactos decorrentes das ações antrópicas notadas neste setor na bacia, dentre os quais estão os conflitos de uso da terra, como comprovam os trabalhos de Souza, (2005), EMBRAPA, (2005), Sucupira, (2006), Nascimento (2006), Alves et. Al. (2005) e Alves, (2007). 
A velocidade de transformação da natureza varia na medida em que se processam os diversos tipos de usos, e quando considerada a atuação do homem com a satisfação das necessidades individuais e coletivas, constata-se que os efeitos se traduzem em modificações da paisagem.

Souza (2000) ao estudar a ecodinâmica das paisagens no Ceará, partilha do mesmo pensamento afirmando que o entendimento da ecodinâmica das paisagens é um requisito necessário e indispensável para um melhor aproveitamento dos recursos naturais.

Sobre a ecodinâmica das paisagens no Ceará, Souza, 2000, afirma que as planícies fluviais são ambientes "resultantes de uma evolução recente da paisagem", uma vez que existem materiais de granulometrias diferentes no alto curso, materiais mais finos e arenosos no meio e baixo curso, como resultado da ação hidroclimática na região e que a faixa litorânea é mais afetada pelos agentes dinâmicos atuais como ventos, correntes e marés, que juntamente com a ação antrópica são os principais responsáveis pelas modificações nesses ambientes.

Neste trabalho foram elaborados mapas temáticos da área por meio de técnicas de geoprocessamento a partir de imagens orbitais dos anos 1985, 2001 e 2014, demonstrando a evolução deste ambiente.

\section{Caracteristicas da área de estudo}

Neste trabalho foi utilizada a classificação geomorfologia proposta por Pritchard (1954), que ordena os sistemas estuarinos em três tipos. Os do tipo planície costeira, os estuários do tipo fiordes e os estuários formados por barras. A figura 1 situa o estuário do rio Acaraú entre as cidades de Cruz e Acaraú posicionado também em relação as atividades de uso da terra.

O estuário do rio Acaraú enquadra-se nos estuários formados em planície costeira que tem sua origem relacionada à transgressão do mar no Holoceno. Miranda et. al.,(2002) afirma que, O processo de inundação foi muito mais acentuado do que o de sedimentação e a topografia atual tornou-se muito semelhante ao vale do rio. 


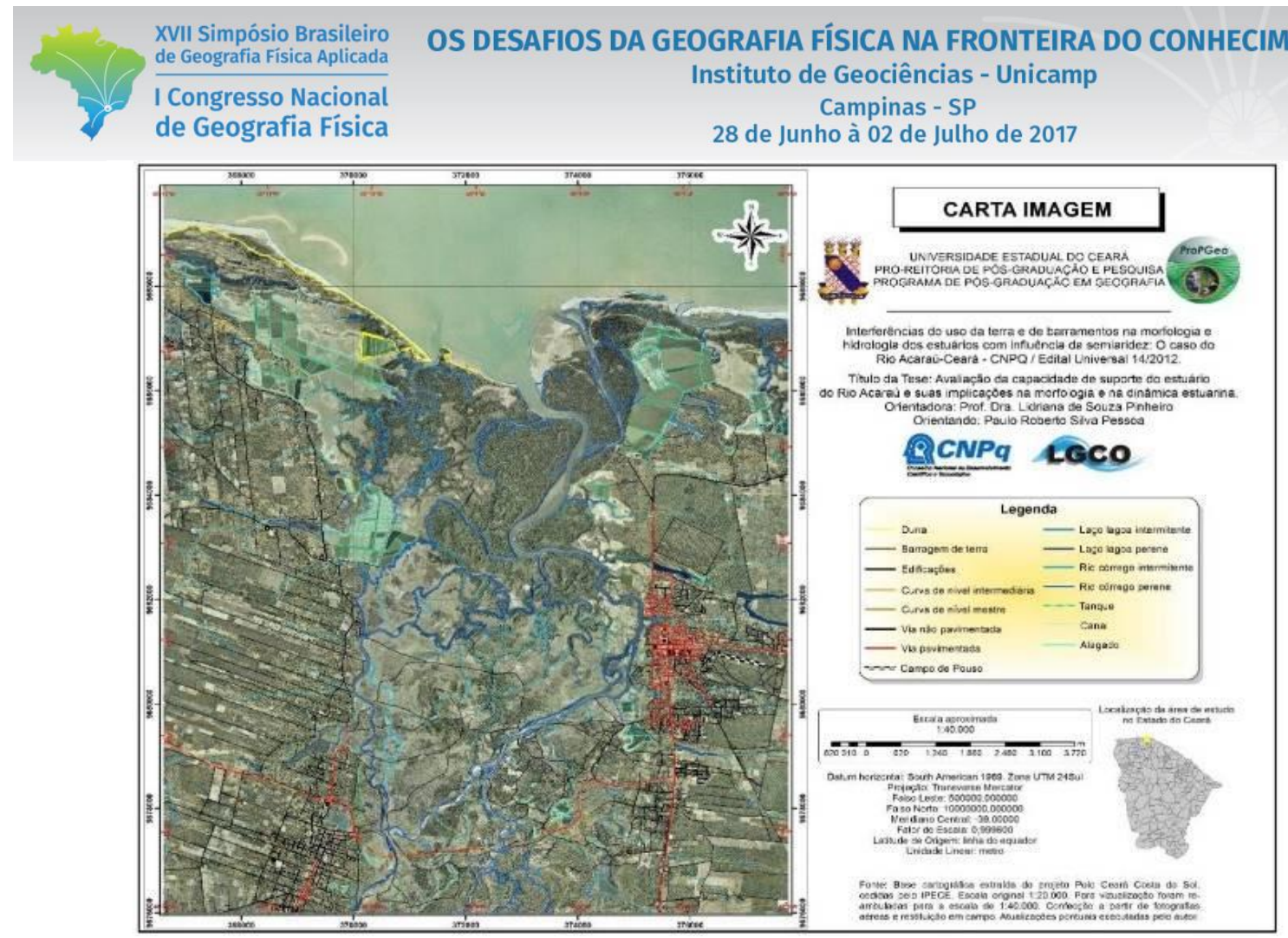

Figura 1 - Localização e posicionamento do estuário do rio Acaraú.

Outras características desse tipo de estuário são a pouca profundidade, geralmente nunca superior a 30 metros e devido ao processo recente de sedimentação, o fundo é preenchido com lama e sedimentos finos na sua parte superior, enquanto que em direção a foz, os sedimentos tornam-se mais grosseiros (Miranda et. al.,2002).

$\mathrm{Na}$ Bacia do rio Acaraú, o relevo apresenta-se dividido em cinco brandes domínios geomorfológicos, representados pelo Planalto da Ibiapaba, pelos maciços residuais, pela depressão sertaneja, pelos tabuleiros costeiros e pela planície costeira, que por sua vez integram-se a paisagem interagindo com os processos de erosão e acumulação. Esta descrição geomorfológica da Bacia do Acaraú baseia-se em Souza, 1988. A partir da interpretação das imagens constatou-se que a faixa praial e os campos de dunas ocupam uma área de pouco mais de $3 \mathrm{~km}^{2}$, correspondendo a $2 \%$ da área. Estes ambientes sofrem a atuação de processos dinâmicos e erosivos ativos que contribuem sobremaneira no processo da morfodinâmica praial. Verificou-se também, em função da dinâmica local, um grande aporte de sedimentos, inclusive formando dunas frontais móveis ativas a partir da faixa praial.

A instabilidade da faixa praial é percebida nitidamente em vários setores da área, porém no distrito de Aranaú onde verificou-se que a praia era ocupada por diversas barracas e possuía um largo estirâncio que foi erodido expondo lentes de matéria orgânica e argila que possivelmente, constituíam ambientes de um paleomangue. 


\section{OS DESAFIOS DA GEOGRAFIA FÍSICA NA FRONTEIRA DO CONHECIMENTO \\ Instituto de Geociências - Unicamp \\ Campinas - SP \\ 28 de Junho à 02 de Julho de 2017}

Na planície flúvio-marinha percebe-se um padrão meandrante e em alguns trechos, anastomótico, com presença de bancos de areia e de margens de erosão e deposição de sedimentos bem definidas.

No caso do canal principal do rio, verifica-se uma intensa contribuição de sedimentos de origem marinha associada a possível atuação do transporte eólico, o que se sugere como fatores responsáveis pelo grande assoreamento atual da desembocadura.

\section{Metodologia}

A primeira etapa do trabalho constou da análise dos compartimentos geoambientais que se apresentam na área de trabalho, definidos pelo estuário do rio Acaraú e suas planícies fluvio-marinha e fluvial, a área correspondente a faixa praia, as áreas de salgado e apicum e os tabuleiros pré-litorâneos. Deve ser destacado que em todos esses espaços há uma relação de uso e ocupação que atuam fortemente na transformação da paisagem neste setor do litoral do Ceará.

Foram realizadas campanhas de campo para delimitação a área de estudo que compreende majoritariamente o estuário do rio Acaraú, limitado longitudinalmente deste a sua foz até a cidade de Cruz - CE, onde verificou-se o limite da influência marinha através das medidas de salinidade, desta forma a salinidade foi considerada como elemento limitante para delimitação do sistema estuarino, assim como a área de influência máxima das marés. Esse limite foi coincidente com o encontrado por Sucupira (2006). Para a determinação da salinidade, foram considerados os padrões estabelecidos pela resolução CONAMA, 357/2005.

$\mathrm{Na}$ etapa de reconhecimento das feições geoambientais na área de trabalho foi considerado também a percepção dos agentes que contribuem para a dinâmica ambiental, além da salinidade e das marés, também forma considerada a própria morfologia do estuário. Também foram considerados elementos como a identificação e o mapeamento dos principais tipos de impactos ambientais associados às formas de uso que afetam o estuário do rio Acaraú.

Paralelamente procedeu-se a elaboração da cartografia temática a partir das imagens obtidas passives de utilização satisfatória. As cartas imagem e os mapas foram confeccionados a partir das imagens disponíveis do United States Geological Survey C/ Landsat Archives. Foram considerados os anos de 1985, 2001 e 2014 em virtude de situação de uso das imagens que apresentaram uma boa resolução e não tinham cobertura de nuvens. Também foram utilizadas imagens de satélite QuickBird fornecidas pelo Instituto de Pesquisa e Estratégia Econômica do Ceará - IPECE do ano de 2010, na escala original de 1: 20.000, posteriormente tratada em software do tipo SIG, ficando com escala de 1: 40.000. 


\section{OS DESAFIOS DA GEOGRAFIA FÍSICA NA FRONTEIRA DO CONHECIMENTO \\ Instituto de Geociências - Unicamp \\ Campinas - SP \\ 28 de Junho à 02 de Julho de 2017}

\section{Resultados e Discussões}

$\mathrm{Na}$ área de estudo a ecodinâmica compreende quatro ambientes distintos, porém intimamente relacionados que são os tabuleiros costeiros, a planície fluvial, a planícies fluvio-marinha e a faixa praial. Figura 2.

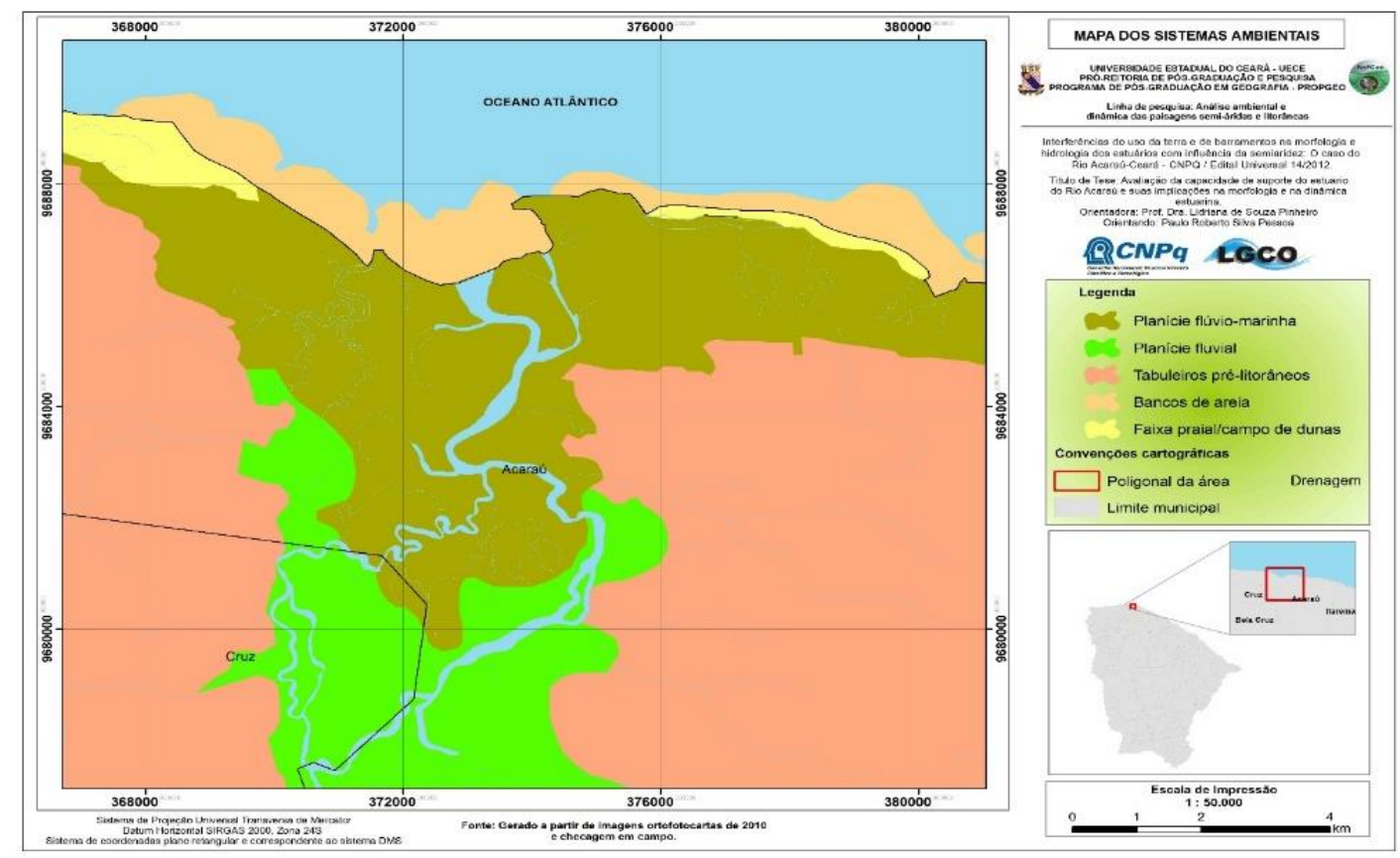

Figura 2 - Mapa de sistemas ambientais da região estuarina do rio Acaraú.

Os tabuleiros costeiros ou pré-litorâneos tem usos diversos que vão desde as áreas de vegetação natural, até o uso por culturas diversas de subsistência, extrativismo vegetal, fruticultura e água subterrânea, além de abrigarem as áreas urbanas das cidades de Acaraú e Cruz.

Os principais impactos relacionados nesses ambientes nos municípios de Acaraú e Cruz são o desmatamento que favorece e intensifica a erosão dos solos com redução das espécies endêmicas vegetais e a mineração para retirada de argila e areias para a construção civil. Contudo estas áreas são utilizadas para o agroextrativismo, expansão das áreas urbanas, pecuária extensiva e como fornecedora de materiais para a construção civil.

As suas principais limitações estão relacionadas a baixa fertilidade natural dos solos e a deficiência de recursos hídricos durante o período seco. Do ponto de vista da ecodinâmica destes ambientes na região estudada foram mapeados e considerados como ambientes estáveis e com vulnerabilidade baixa à ocupação e uso do solo.

Geologicamente os tabuleiros pré-litorâneos, são formados a partir de sedimentos tércio-quaternários de matriz areno-argilosa. A Formação Barreiras ocorre em toda a extensão do litoral cearense com uma 


\section{OS DESAFIOS DA GEOGRAFIA FÍSICA NA FRONTEIRA DO CONHECIMENTO \\ Instituto de Geociências - Unicamp \\ Campinas - SP \\ 28 de Junho à 02 de Julho de 2017}

largura variável em relação ao continente. Em alguns setores da costa cearense esta Formação tem se pronunciando até a faixa praial e mesmo em alguns locais da plataforma continental interna rasa.

Na região do estuário do Acaraú os tabuleiros costeiros ocupam uma área de aproximadamente $92 \mathrm{~km}^{2}$, ou seja, $51 \%$ de toda a área estudada. Tabela 1 . As porções terminais dos tabuleiros em transição com as planícies fluviais possuem alturas variáveis, pois acompanham o caimento do restante dos tabuleiros em direção à costa.

Tabela 1 - Sistemas ambientais e suas respectivas áreas

\begin{tabular}{l|c|c}
\multicolumn{1}{c|}{ SISTEMAS AMBIENTAIS } & ÁREA $\left.\mathbf{( k m}^{\mathbf{2}}\right)$ & $\%$ \\
\hline Bancos de Areia & 10,04 & 5,00 \\
\hline Faixa de Praia /Campo de Dunas & 3,44 & 2,00 \\
\hline Planície Flúvio-Marinha & 44,98 & 25,00 \\
\hline Tabuleiro Pré-Litorâneo & 92,37 & 51,00 \\
\hline Planície Fluvial & 30,03 & 17,00 \\
\hline
\end{tabular}

A planície fluvial do rio Acaraú no trecho entre Cruz e Acaraú tem o seu uso relacionado às culturas de subsistência, a ocupação imobiliária, extração de água para consumo e irrigação, extração da palha e cera de carnaúba, extração de argila e pesca artesanal.

Os principais impactos ambientais encontrados foram a degradação da mata ciliar, assoreamento do leito fluvial, poluição hídrica, salinização dos solos, despejo de efluentes, resíduos sólidos, poluição dos solos e dos recursos hídricos.

A capacidade de suporte da planície fluvial do rio Acaraú no trecho estudado aponta como principais limitações a intermitência fluvial, a drenagem imperfeita dos solos, áreas sujeitas a alagamentos e inundações periódicas. Contudo apresentam potencial para o desenvolvimento do ecoturismo, da pesca artesanal e agroextrativismo, além do uso para lavouras irrigadas e um bom potencial para uso e captação de água.

A ecodinâmica destes ambientes na região estudada demostram que são ambientes de transição com tendência e instabilidade com vulnerabilidade alta à ocupação.

Na planície fluvio-marinha os usos mais expressivos encontrados foram a ocupação imobiliária, áreas ocupadas pela agricultura familiar de subsistência e grandes áreas ocupadas pelos tanque de cultivo de camarão. Dentre os impactos presentes estão o assoreamento dos canais estuarinos, o desmatamento das margens e perda da diversidade florística, despejos de efluentes, resíduos sólidos e outros detritos. 
Algumas das principais potencialidades de ambiente são o uso para o ecoturismo e educação ambiental, preservação da biodiversidade e valor paisagístico. As limitações são a forte tendência a alagamentos periódicos das marés e as restrições de uso legal.

A ecodinâmica destes ambientes os definem como sendo ambientes fortemente instáveis e com vulnerabilidade alta à ocupação.

O setor correspondente a planície costeira registra dentre as principais formas de uso a pesca de subsistência, barracas de praia em Aranaú e Coroa Grande, atividade de lazer e carcinicultura.

Os impactos evidenciados na área são a ocorrência de poluição / contaminação dos recursos hídricos, despejo de efluentes e resíduos sólidos.

Nesta porção da área são severas as limitações quanto a inundações periódicas e implantação de loteamentos devido a dinâmica eólica. A ecodinâmica destes ambientes os caracterizam com ambientes fortemente instáveis e com vulnerabilidade alta à ocupação.

\subsection{Evolução das Paisagens}

Considerando a classificação das imagens multitemporais dos anos de 1985, 2001 e 2014 foram estabelecidas cinco classes principais para compreender a evolução desse ambiente. As classes correspondem as áreas de mangue, os tanques de carcinicultura, os agroecossitemas que abrigam as atividades de agricultura irrigada e de subsistência, além dos corpos hídricos e das feições de dunas e faixa praial.

Na década de 1985 a pressão sobre os ambientes naturais que compõe a região estuarina do rio Acaraú $\mathrm{CE}$, já começa a surgir. Inicialmente com as atividades relacionadas a pesca da lagosta e o grande fluxo de embarcações que faziam porto em Acaraú, posteriormente com a expansão urbana, percebe-se a intensificação do desmatamento da vegetação de mangue e introdução da carcinicultura, que ocorre somente em meados dos anos 1990. Figura 3.

As áreas correspondentes ao manguezal tiveram uma visível redução. Em 1985 a vegetação de mangue ocupava uma área de $87,85 \mathrm{~km}^{2}$, e o estuário ainda não apresentava grandes alterações do ponto de vista de impactos ambientais. 

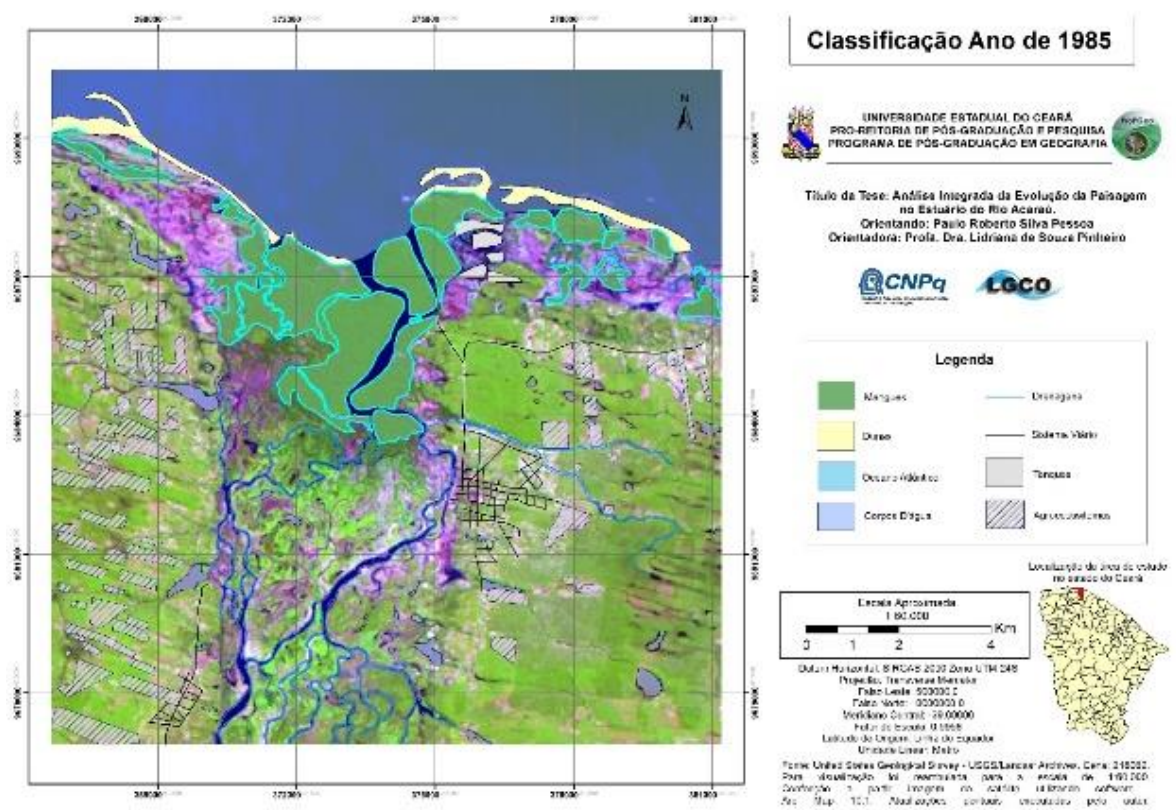

Figura 3 - Mapeamento das condições de uso da terra em 1985.

No mapa da figura 3, que mostra a região em 1985, consegue-se identificar dentre as formas de ocupação principal, os agroecossistemas, que ocorrem nas áreas correspondentes aos tabuleiros costeiros prélitorâneos.

Observa-se na imagem também alguns reservatórios de pequeno porte que compõem a drenagem na área do estuário, além de outras áreas no tabuleiro e nas planícies fluviais e fluvio-marinhas que ainda não haviam sido ocupadas.

A área urbana era menor que a atual, mas dispunha de arruamentos bem definidos e ocupação bem caracterizada, que já exercia pressão sobre a planície fluviomarinha do rio.

A planície litorânea é composta pela faixa de praia, campo de dunas, planície fluvio-marinha e a planície fluvial, que naquele contexto histórico apresentava taxas de ocupação relativamente baixa, pequenas construções de madeira e palha que serviam de base de apoio para pescadores e se constituíam como a principal forma de ocupação do espaço litorâneo.

Contudo na classificação da imagem de 2001, observa-se que a vegetação de mangue já sofreu uma severa redução, correspondendo apenas $20 \mathrm{~km}^{2}$, o que equivale somente a $24,13 \%$ da cobertura originalmente observada em 1985. Neste período a redução da área de mangue foi de $75,86 \%$ em relação a área que esse sistema ocupava em 1985. Neste período que corresponde a 16 anos foram degradados $66,65 \mathrm{~km}^{2}$ de mangue. Figura 4. 


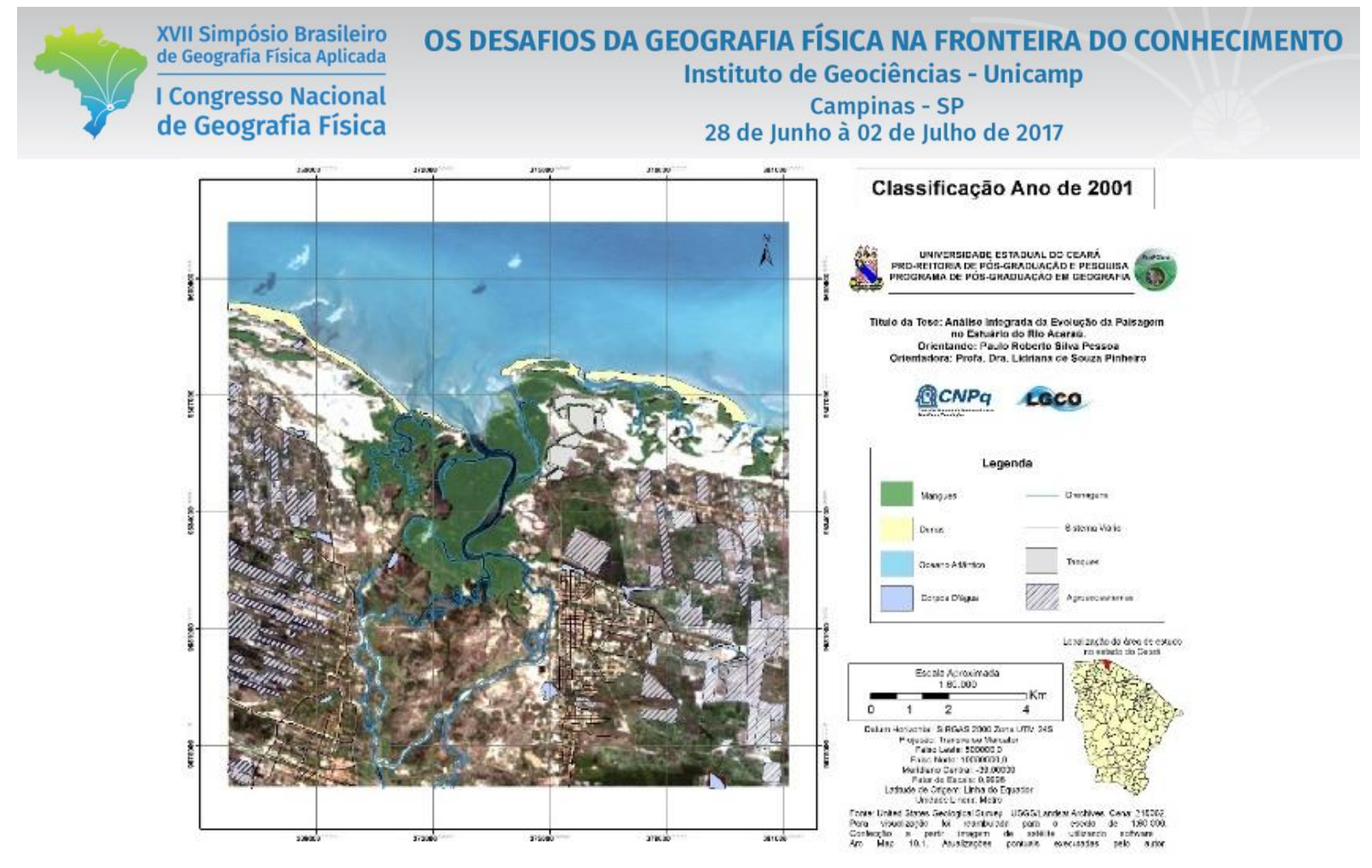

Figura 4- Mapeamento das condições de uso da terra em 2001.

$\mathrm{Na}$ interpretação da imagem de 2014, apresentada na figura 5, com relação a cobertura de mangue, pode se verificar que não houve uma recuperação desse ecossistema, pelo menos no que se refere a área, sendo constatada uma redução ainda maior.
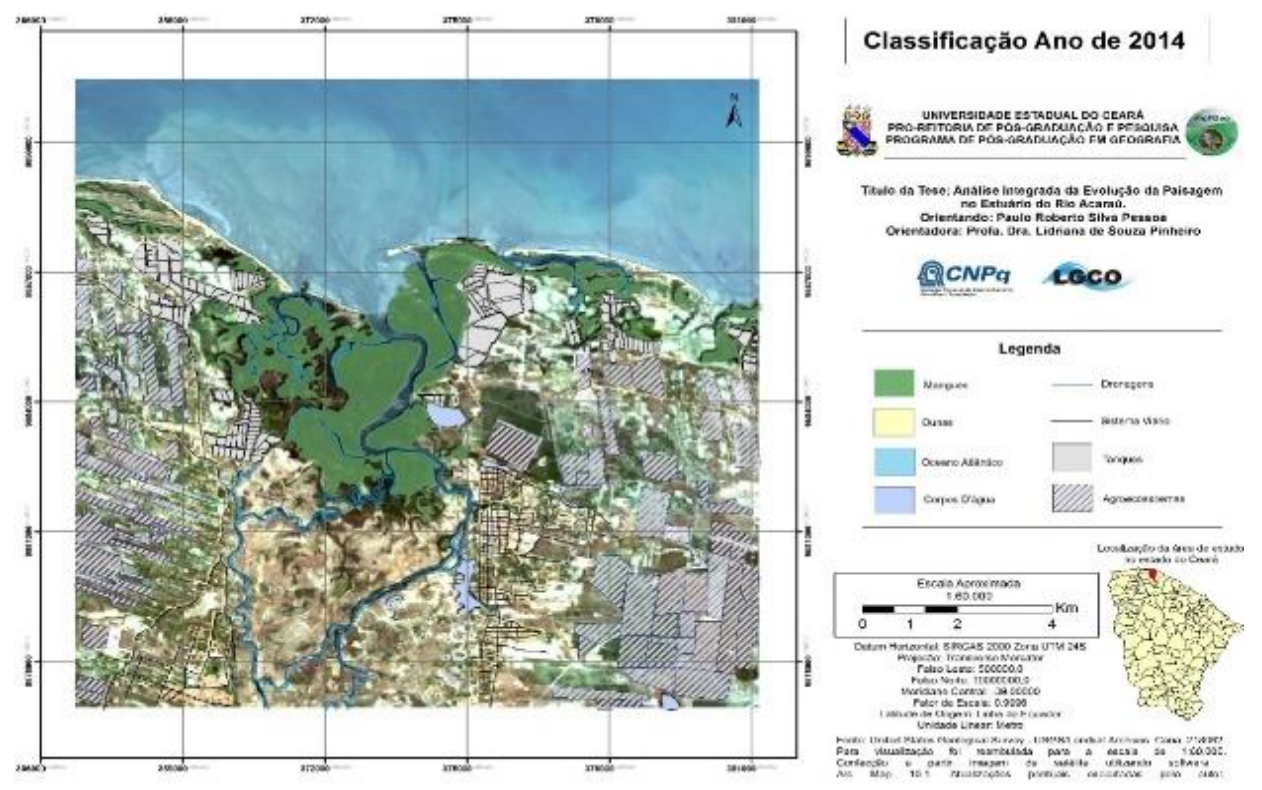

Figura 5- Mapeamento das condições de uso da terra em 2014.

Nesta classificação esse ambiente apresenta uma área no sistema estuarino do rio Acaraú de apenas 16,09 $\mathrm{km}^{2}$, ou seja, a cobertura atual corresponde a apenas $18,31 \%$ da área que ocupava 30 anos atrás. Tabela 2. 
Tabela 2 - Comparativo entre as classes estabelecidas no intervalo das imagens multitemporais.

\begin{tabular}{l|c|c|c}
\hline \multicolumn{1}{c|}{ Cobertura da terra } & $\begin{array}{c}\mathbf{1 9 8 5} \\
\left(\mathbf{A} \mathbf{r e a} / \mathbf{K m}^{\mathbf{2}}\right)\end{array}$ & $\begin{array}{c}\mathbf{2 0 0 1} \\
\left(\mathbf{A} \mathbf{r e a} / \mathbf{K m}^{\mathbf{2}}\right)\end{array}$ & $\begin{array}{c}\mathbf{2 0 1 4} \\
\left(\mathbf{A} \mathbf{r e a} / \mathbf{K m}^{\mathbf{2}}\right)\end{array}$ \\
\hline Mangue & 87,85 & 21,20 & 16,09 \\
\hline Tanques de Carcinicultura & 0,7 & 1,3 & 13,25 \\
\hline Agroecossistemas & 10,56 & 13,52 & 22,46 \\
\hline Corpos dagua/Drenagem & 2,23 & 0,88 & 1,04 \\
\hline Dunas & 2,82 & 2,45 & 1,24 \\
\hline
\end{tabular}

Vários fatores podem ter contribuído para a redução espacial do manguezal. No intervalo observado pode ser comprovado que houve expansão urbana, a cidade avançou sobre alguns setores do mangue, que inclusive encontra-se urbanizado, com a presença de passarelas e quiosques, utilizados como equipamentos urbanos de lazer na cidade de Acaraú.

A expansão da carcinicultura e dos agroecossistemas, assim como as alterações hidroclimáticas ocorridas nos últimos 40 anos certamente também influenciaram neste processo. No entanto das quatro espécies vegetais predominantes no estuário, não foi possível determinar qual a espécie mais ameaçada pelas práticas de degradação.

Chama a atenção a franca expansão da criação de camarão em cativeiro que no intervalo temporal de 30 anos, aproximadamente, passou a ocupar uma área significativa atualmente compreendendo pouco mais de 13,25 Km². Essa atividade ganhou força sobretudo na década de 1990 não só no município de Acaraú, mas em todo litoral cearense de no Nordeste brasileiro. As áreas ocupadas por esta atividade utilizam tanques de antigas salinas, mas também áreas mais nobres como parcelas de terras adjacentes ao estuário e regiões próximas, como se pode comprovar na análise multitemporal das imagens utilizadas neste trabalho.

No munícipio de Acaraú de 2001 a 2014, ou seja, em 13 anos o aumento da área produtora desta atividade foi da ordem de mais $700 \%$. Ocorrendo a implantação de novas fazendas de criação de camarão e também a consolidação das técnicas e tecnologias para a reprodução e manejo o que fez do município um dos mais importantes polos da carcinicultura no Nordeste do Brasil. Atualmente só o município de Acaraú conta com aproximadamente 35 empreendimentos licenciados para operação.

O maior problema relacionado a esta atividade é a qualidade da água da despesca lançada no rio Acaraú, que pode conter altos teores de fósforo e nitrogênio, além de outras substâncias potencialmente poluidoras. 
Contudo os impactos sociais e ambientais dessa atividade também se notabilizaram no ambiente como o desmatamento do mangue, aterro de áreas de mangue, ocupação de áreas de APP, alterações na dinâmica das espécies animais que habitam o estuário, modificação na morfologia dos canais e da topografia, além dos conflitos sociais ocasionados pela posse e o uso de terras e por questões trabalhistas.

Os agroecossistemas presentes na região que representam as culturas de subsistência, as culturas irrigadas e as outras atividades produtivas deste setor, também demonstraram um aumento na sua área quando a comparação é feita em relação aos anos de 1985 a 2014. Este setor teve um aumento na sua área de mais de 12 vezes, ocupando atualmente uma área aproximada de $22,46 \mathrm{Km}^{2}$ na porção circunvizinha ao estuário do rio Acaraú.

\section{Conclusões}

A região estuarina do rio Acaraú é marcada por diversas atividades relacionadas à exploração ou uso dos recursos naturais. Durante os trabalhos de campo foram identificados 11 tipos principais e distintos de atividades ou ações geradoras de impacto que contribuem de alguma maneira para a degradação do ambiente, que podem promover algum tipo de impacto de forma direta e indireta no estuário do rio Acaraú. Estas atividades foram identificadas com a utilização de uma lista controle e verificação.

Dentre as ações e atividades impactantes identificadas na região estuarina podem ser citados o lazer e turismo, o lançamento de esgotos, a ocupação de áreas de preservação permanente - APP, as atividades comerciais, as atividades portuárias e de navegação, a carcinicultura, a mineração e cultivo de coco, a agricultura de subsistência, agroindústria, energia eólica, a produção e ocorrência difusa de resíduos sólidos em vários setores no estuário e também em áreas próximas.

\section{BIBLIOGRAFIA}

ALVES, A. B. Estuário do rio Acaraú: impactos ambientais e implicações na qualidade dos recursos hídricos. Fortaleza 2008. 116p. Dissertação (Mestrado Acadêmico em Geografia) MAG-UECE.

ALVES, A. B. et al. Qualidade da Água do Estuário do Rio Acaraú e Suas Implicações Ambientais (CearáBrasil). V Encontro de Pesquisa e Pós-Graduação, V Encontro de Iniciação Científica e Tecnológica. Fortaleza, CEFET- CE, 2005.

ARAÚJO, Maria Valdirene e Freire, George Satander Sá. Análise ambiental da área estuarina do Rio Acaraú Ceará. Revista de Geologia, Vol. 20, nº 2, 205-218, 2007.

BERTRAND, G. Paisagem e Geografia Física Global - Esboço Metodológico. Caderno de Ciências da Terra $\mathrm{n}^{\circ}$. 13. IGEOG - USP. v. 3, p. 1-21. São Paulo, 1969.

CABRAL, et al. Os estuários do Nordeste do Brasil e o desenvolvimento sustentável: usos múltiplos e impactos. O estuário do rio Timbó como um estudo de caso. Tropical Oceanography, Recife, v.33, n. 2, p. 193 - 204. 2005. 


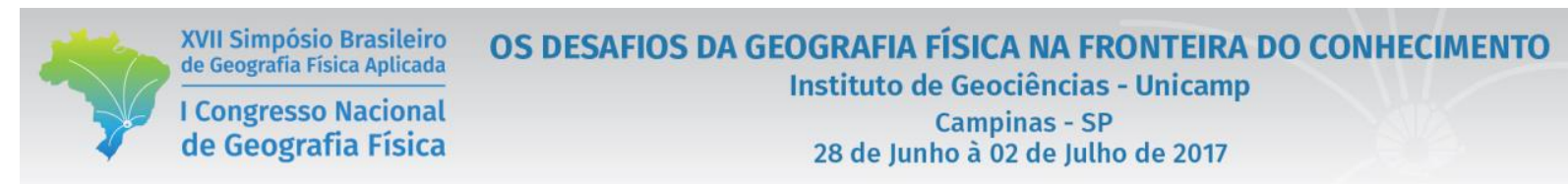

CONAMA - Conselho Nacional do Meio Ambiente. Resolução CONAMA 357/2005. "Dispõe sobre a classificação dos corpos de água e diretrizes ambientais para o seu enquadramento, bem como estabelece as condições e padrões de lançamento de efluentes, e dá outras providências.

DIAS, C.B. Dinâmica do sistema estuarino Timonha/Ubatuba e suas implicações ambientais, Ceará - Brasil. 2005. 145p. Dissertação (Mestrado. Ciências Marinhas tropicais) - Universidade Federal do Ceará, Fortaleza, 2005.

DINIZ, S. F.; et al. Susceptibilidade erosiva do baixo curso do Rio Acaraú-CE. Geociências, v. 27, n. 03, p. 355367, 2008.

EMPRESA BRASILEIRA DE PESQUISAS AGROPECUÁRIAS - EMBRAPA: Agroindústria Tropical. Contexto geoambiental das Bacias hidrográficas dos rios Acaraú, Curu e baixo Jaguaribe - estado do Ceará. Fortaleza. 52p. Documentos 101, 2005.

MIRANDA, L. B. de; CASTRO, B. M. de; KJERFVE, B. Princípios de oceanografia física de estuários. São Paulo: Editora da Universidade de São Paulo, 2002.

MORAIS, J.O.; PINHEIRO, L. S. The effect of semi-aridity and damming on sedimentary dynamics in estuaries-Northeastern region of Brazil. Journal of Coastal Research, v. 64, p. 1540-1544, 2011.

NASCIMENTO, F. R. Degradação Ambiental e Desertificação no Nordeste Brasileiro: O contexto da Bacia do Rio Acaraú - Ceará. Tese de doutorado em Geografia. Universidade Federal Fluminense, 2006.

PESSOA, P. R. S. Analise Integrada da Evolução da Paisagem no Estuário do Rio Acaraú. 2015. Tese (Programa de Pós-Graduação em Geografia). Universidade Estadual do Ceará - UECE. Fortaleza-CE.

PINHEIRO, L. S. Riscos e gestão ambiental no estuário do rio Malcozinhado, Cascavel - CE. 2003. 165p. Tese (Doutorado em Oceanografia) - Universidade Federal de Pernambuco, Recife, 2003.

PINHEIRO, L. S.; MORAIS, J.O. Interferências de barramentos no regime hidrológico do estuário do rio CatúCeará-Nordeste do Brasil. Sociedade \& natureza (UFU. Online), v. 22, p. 237-250, 2010.

SANCHES, L. Avaliação de Impactos Ambientais: conceitos e métodos. Oficina de Textos. 2006.495 p.

SOUZA, Marcos José Nogueira de. Contribuição ao Estudo das Unidades Morfo-estruturais do Estado do Ceará. Fortaleza: Revista de Geologia, v. 1, p. 73-91, jun. 1988.

SOUZA, Marcos José Nogueira. Diagnóstico Geoambiental da Bacia hidrográfica do rio Acaraú. Relatório Preliminar. Fortaleza: UECE/EMBRAPA/UFF/COGEHR. 2005. p 99.

SOUZA, M. J. N. Compartimentação Territorial e Gestão Regional do Ceará. Demócrito Rocha. Fortaleza, 2000 .

SUCUPIRA, P. A. P. Indicadores de degradação ambiental dos recursos hídricos superficiais no médio e baixo vale do rio Acaraú - CE. 2006. 242 p. Dissertação (Mestrado em Geografia) - Universidade Estadual do Ceará, Fortaleza, 2006.

TRICART, Jean. Ecodinâmica. Rio de janeiro, IBGE, Diretoria Técnica, SUPREN,1977. 95p. 